\title{
New Developments in Anti-Anginal Therapy: Roles of Ivabradine, Allopurinol and of Agents Modifying Myocardial Metabolism
}

\author{
Thanh H. Nguyen 1,2, Cher-Rin Chong1,2, Wai P. Chan 1,2, John D. Horowitz ${ }^{1,2 *}$ \\ ${ }^{1}$ Department of Cardiology, The Queen Elizabeth Hospital, Woodville South, Australia \\ ${ }^{2}$ Basil Hetzel Institute, The University of Adelaide, Adelaide, Australia \\ Email: ${ }^{\text {john.horowitz@adelaide.edu.au }}$
}

Received 19 April 2014; revised 30 May 2014; accepted 16 June 2014

Copyright (C) 2014 by authors and Scientific Research Publishing Inc.

This work is licensed under the Creative Commons Attribution International License (CC BY).

http://creativecommons.org/licenses/by/4.0/

(c) (i) Open Access

\begin{abstract}
Over the last 20 years, it has emerged that, while surgical revascularisation of extensive ischaemic heart disease may have prognostic advantages, the main issues considered regarding individual management are usually those of symptomatic improvement only. The major impetus towards invasive intervention is therefore failure of prophylactic anti-anginal therapy. On the other hand, many patients, especially the elderly, now present the clinical problem of ongoing angina without residual invasive options. There is an ongoing need for more effective anti-anginal therapies. Of the currently available major classes of prophylactic anti-anginal agents, neither nitrates, $\beta$-blockers nor calcium antagonists generally produce marked improvements in exercise duration. Three areas of new therapeutic development in anti-anginal therapy are worthy of note. These involve the sinus node inhibitor ivabradine, high dose allopurinol (xanthine oxidase inhibitor) and a new class of "metabolic modulators" represented by perhexiline, trimetazidine and probably ranolazine. The current review addresses the therapeutic potential of these agents. Notably, all of these "new" drugs are potentially suitable for management of angina in the setting of impaired left ventricular systolic function, and they may also be utilized in patients with angina independent of the presence of coronary disease (for example in hypertrophic cardiomyopathy). The current evidence for efficacy and potential future development in this area are reviewed.
\end{abstract}

\section{Keywords}

Anti-Anginal Therapy, Myocardial Metabolism, Stable Angina Pectoris, Ivabradine, Allopurinol

\footnotetext{
${ }^{*}$ Corresponding author.
} 


\section{Introduction}

"If I were an ischaemic cardiac cell, and someone offered me drugs or blood, I think I'd take blood!”

-Dr. W. Paulus, 1986

The history of development of anti-ischaemic therapy for angina pectoris has been bedevilled by the notion that a strategy of predominantly medical treatment is essentially palliative, while interventional restoration of normal coronary haemodynamics is "curative". Interestingly, evidence to support this philosophy in patients with stable angina is very limited, beyond the findings of the CASS study more than 25 years ago [1]. Notably, the results of the COURAGE trial [2] challenge the idea that coronary stenting should play a primary role in such patients.

If therefore the major efficacy of drugs of surgical/percutaneous intervention relates to amelioration of symptoms in patients with angina, how effective are our "core" medical anti-anginal therapies? The major groups of prophylactic anti-anginal agents are long-acting nitrates, $\beta$-blockers and calcium antagonists (especially nondihydropyridine agents such as verapamil and diltiazem). The key findings from studies of mono-therapy with these agents are summarized in Table 1, and the "core" mechanisms of action of these agents are schematized in Figure 1.

In general, these show that long-acting nitrates and $\beta$-blockers induce only small prolongations of exercise duration, while both verapamil and diltiazem are a little more effective. On the other hand, there is no evidence that any of these forms of therapy improves long-term outcomes in patients with stable angina (although admittedly $\beta$-blockers have prognostic utility if patients have concomitant heart failure). Indeed, there is a concern that long-acting nitrates may have a number of important disadvantages, including potential aggravation of endothelial dysfunction [3] and also the precipitation of "rebound" ischaemia [4]. Interestingly, nicoradil, an organic nitrate/potassium channel activation, appears to reduce risk of hospitalization during chronic therapy [5] although the mechanism(s) of this beneficial effect remain uncertain.

The clinical characteristics of patients treated medically for angina pectoris have also evolved with the relatively widespread availability of coronary surgery/stenting. In most societies, such patients now tend to be elderly, with multiple comorbidities. Many such patients have undergone surgical interventions previously and are technically unsuitable for further invasive procedures: many have concomitant severe impairment of left ventri-

Table 1. Placebo-controlled studies of efficacy of long-acting nitrates, $\beta$-blockers, and calcium antagonists in prolonging exercise duration in stable angina pectoris.

\begin{tabular}{|c|c|c|c|c|}
\hline Study & Agent & \multirow{2}{*}{$n$} & $\%$ exercise & \multirow{2}{*}{$p$} \\
\hline (Category/Authors) & (Daily dose) & & prolongation & \\
\hline \multicolumn{5}{|l|}{ 1. Nitrates } \\
\hline Parker et al., 1995 [40] & Nitroglycerine (patches $0.4 \mathrm{mg} / \mathrm{h}$ for $12 \mathrm{hrs}$ ) & 291 & 16 & $<0.001$ \\
\hline Chrysant et al., 1993 [41] & Isosorbide-5-mononitrate (240 mg) & 313 & 18 & $<0.01$ \\
\hline \multicolumn{5}{|l|}{ 2. $\beta$-blockers } \\
\hline Jamal et al., 1987 [42] & Carvedilol (50 mg) & 12 & 24 & $<0.05$ \\
\hline \multirow[t]{2}{*}{ Schnellbacher et al., 1986 [43] } & Bisoprolol: $10 \mathrm{mg}$ & 12 & 22 & $<0.05$ \\
\hline & $20 \mathrm{mg}$ & & 31 & \\
\hline DiBianco et al., 1980 [44] & Acebutolol (1155 mg) & 44 & 14 & $<0.01$ \\
\hline Schwartz et al., 1981 [45] & Atenolol (100 - 200 mg) & 12 & 32 & $<0.01$ \\
\hline \multicolumn{5}{|l|}{ 3. Calcium antagonists } \\
\hline Hung et al., 1983 [46] & Diltiazem (360 mg) & 12 & 31 & $<0.05$ \\
\hline Pine et al., 1982 [47] & Verapamil (240 - 480 mg) & 18 & 42 & $<0.001$ \\
\hline Andreasen et al., 1975 [48] & Verapamil (240 mg) & 47 & 20 & $<0.05$ \\
\hline
\end{tabular}




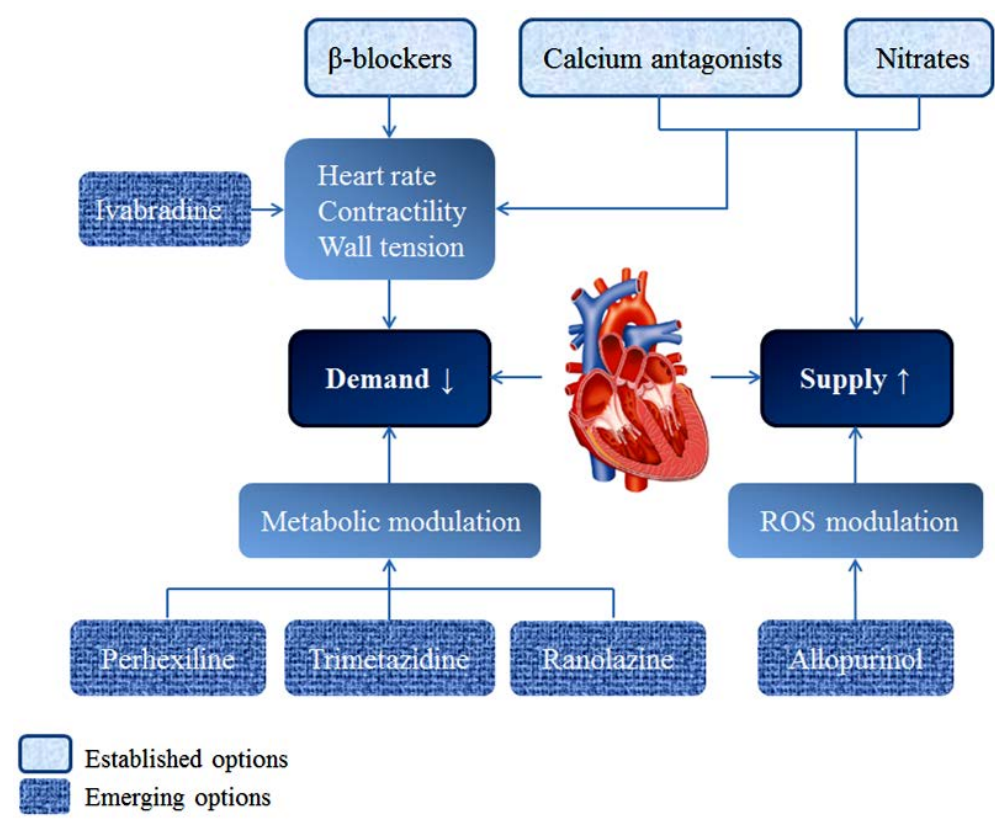

Figure 1. Determinants of therapeutic amelioration of myocardial ischaemia: emerging options (ROS: reactive oxygen species).

cular systolic function. In such individuals, there is a clear-cut need for a transition to "new" anti-anginal therapies. Notably, treatment with verapamil or diltiazem is contra-indicated in the presence of severe systolic heart failure [6].

This review addresses the evolving role of a number of newly recognised/developed anti-anginal agents in the setting of "difficult" angina pectoris. The major sites of action of these agents in ameliorating ischaemia are schematized in Figure 1. A potential role for all of these agents in angina pectoris refractory or unsuitable for $\beta$-blockers or calcium antagonists was also included in current textbook recommendations [7].

\section{Ivabradine}

Ivabradine is a sino-atrial node inhibitor which specifically inhibits the If channel of pacemaker cells, leading to a reduction in both resting and exercise-induced heart rate and improvement in myocardial $\mathrm{O}_{2}$ balance. It has no effect on other intracardiac conduction system as well as on blood pressure and myocardial contractility. Because of these limited sites of action, it will not induce bronchospasm (unlike $\beta$-blockers), it is devoid of interactions with diabetic status, and does not adversely affect symptomatic status in the presence of systolic heart failure. On the other hand, it is totally ineffective in patients with no sinus node activity (e.g. atrial fibrillation).

To date, ivabradine has been evaluated as an anti-anginal agent both in monotherapy and in combination with $\beta$-blockers, as summarized in Table 2. In both circumstances, there was a moderate increase in exercise duration. The only common adverse effects seen were those of phosphenes (flashing lights) development, due to If current inhibition in the retina. Interestingly, recent clinical trial developments with ivabradine have focused mainly on its role as a secondary treatment in heart failure [8]. No long-term data are available regarding effects on cardiovascular events.

\section{High Dose Allopurinol}

One other agent that has been proposed as an anti-anginal recently is allopurinol, a xanthine oxidase inhibitor. Allopurinol has been traditionally used in the treatment of gout. The application of allopurinol in coronary artery disease is based on previous evidence that xanthine oxidase is a potent mediator of oxidative stress. Indeed early studies have shown the potential of allopurinol to reduce vascular oxidative stress and thereby improve endothelial function [9]. Furthermore, alterations in cardiac metabolism, primarily in oxygen consumption and contractility have been demonstrated in heart failure models with allopurinol [10] [11]. 
Table 2. Placebo-controlled studies of anti-angina efficacy of ivabradine in prolonging exercise duration in stable angina pectoris: (a) monotherapy, (b) addition to $\beta$-blockers.

\begin{tabular}{|c|c|c|c|c|c|}
\hline Study & \multirow{2}{*}{ Antecedent therapy } & \multirow{2}{*}{ Daily dose } & \multirow{2}{*}{$n$} & $\%$ exercise & \multirow{2}{*}{$p$} \\
\hline (Category/Authors) & & & & prolongation & \\
\hline \multicolumn{6}{|l|}{ 1. vs. placebo } \\
\hline \multirow[t]{2}{*}{ Borer et al., 2003 [49] } & - & $10 \mathrm{mg}$ for 2 weeks then & 360 & 9 & 0.02 \\
\hline & - & $20 \mathrm{mg}$ for 2 - 3 months & & 18.5 & - \\
\hline \multicolumn{6}{|l|}{ 2. Add-on therapy } \\
\hline \multirow[t]{2}{*}{ Tardif et al., 2009 [50] } & Atenolol $50 \mathrm{mg}$ & $10 \mathrm{mg}$ for 2 months then & 889 & 4 & 0.02 \\
\hline & & $15 \mathrm{mg}$ for 2 months & & 5 & $<0.001$ \\
\hline
\end{tabular}

The first randomized double-blind placebo controlled trial of the use of allopurinol in the management of stable angina, offered promising results. In this study, 65 patients with documented coronary artery disease and positive exercise test were randomized to receive high dose allopurinol, $600 \mathrm{mg}$ a day on top of a standard treatment, in a double-blinded controlled trial [12]. Allopurinol use was associated with a median increase in exercise time to ST-segment depression of 43 seconds $(p=0.0002)$, a median increase in total exercise time of 58 seconds ( $p=0.0003$ ), and a median increase in time to chest pain of 38 seconds $(p=0.001)$. These findings were backed up by a second study by the same group, which explored the potential mechanisms of the benefits of allopurinol in 80 patients with stable coronary artery disease, on maximal anti-anginal treatment [13]. Endothelial function was assessed by forearm venous occlusion plethysmography, flow-mediated dilation, and pulse wave analysis and vascular oxidative stress was assessed by intra-arterial co-infusion of vitamin $\mathrm{C}$ and acetylcholine. They found that indeed allopurinol use was associated with improved endothelium-dependent vasodilation, by both forearm venous occlusion plethysmography ( $93 \% \pm 67 \%$ vs. $145 \% \pm 106 \%, p=0.006)$ and flow-mediated dilation $(4.2 \% \pm 1.8 \%$ vs. $5.4 \% \pm 1.7 \%, p<0.001)$. Arterial stiffness was also improved significantly (central augmentation index improved by $2.6 \% \pm 7.0 \%, p<0.001$ ), and furthermore, vascular oxidative stress was completely abolished by allopurinol.

However, these studies are small and although no adverse effects were reported, further data in regards to safety and impact on long term cardiovascular outcomes in larger studies are prudent. More importantly, it is as yet unclear whether addition of allopurinol to other anti-anginal drugs improves long-term prognosis in patient with CAD. We have also seen benefits in similar small animal and human studies with allopurinol in congestive heart failure [9], and yet the recent large clinical trial OPT-CHF in 405 patients failed to produce any clinical benefits [14].

\section{Agents Modifying Myocardial Metabolism}

The association of exertional ischaemia with impairment of myocardial energetics raises the option of addressing this problem without either limiting myocardial work (for example by preventing tachycardia and/or exercise-induced increases in contractile function) or by improving coronary haemodynamics.

In theory, the generation of high energy phosphates by the myocardium should be critical to maintenance of homeostasis irrespective of whether the underlying problem is limitation of myocardial perfusion, increased left ventricular afterload (for example with aortic valvular stenosis) or even impairment of systolic and/or diastolic left ventricular dysfunction. However, pharmacological manipulation of myocardial energetics has been a slowly evolving area.

Initial attempts to "feed the heart" were associated with treatment for evolving myocardial infarction, where the glucose-insulin-potassium (GIK) treatment algorithm was proposed and then tried extensively (for review see [15]). Interestingly, this idea of promoting glucose uptake and utilization has generally been unsuccessful, with the possible exception of prevention of myocardial ischaemia associated with open-heart surgery [16].

Subsequently, there have been extensive developments of drugs which potentially affect myocardial energetics during chronic oral administration. Some of these agents inhibit long-chain fatty acid catabolism, whether via inhibiting the "carnitine shuttle" (which controls their uptake into mitochondria) or fatty acid oxidases. Such 
agents may activate the so-called "Randle shift": a process of transition to more oxygen-efficient ATP generation from glucose utilization [17].

However, it appears possible to improve efficiency of myocardial oxygen utilization by more than the $13 \%$ 15\% expected from activation of a "Randle shift" [18]. Many of the agents concerned exert multiple effects, including interactions with "energy sensor" such as AMP kinase (AMPK) and the pro-oxidant thioredoxin-interacting protein (TxNIP). Specifically, metformin, which reduces mortality in diabetics, is an AMPK activator, and ACE inhibitors, among their many effects, reduce TxNIP expression. Amiodarone, apart from its anti-anginal effects through $\beta$-blockade/calcium channel blockade, also blocks the "carnitine shuttle" [19].

However, of the numerous agents with "metabolic" anti-ischaemic actions, there are of particular significance: perhexiline, trimetazidine and ranolazine. These will be discussed more fully.

\subsection{Perhexiline}

Perhexiline is a myocardial "metabolic" agent that was introduced in the 1970s as a prophylactic anti-anginal agent which was initially presumed to be a coronary vasodilator. Perhexiline proved to be an extremely effective treatment for exertional angina, whether in monotherapy [20] or in combination with other agents [21]. Despite its early success, its use was rapidly declined after reports of serious hepato- and neurotoxicity associated with long-term administration, which was poorly understood at that time. In the mid 1980s, many countries removed it from their markets following those reports. However, hepato- and neurotoxicity was later recognised to be attributable to drug accumulation, by virtue of inter-individual variability in pharmacokinetics, due to genetic polymorphism of cytochrome P450 2D6. Subsequently, significant long-term side effects were shown to be largely eliminated by dosage adjustment according to plasma perhexiline concentrations [22] [23].

Although there were early proposals about the potential "myocardial metabolic" effects of perhexiline, it was not until in 1996 [19] (almost 30 years after it was used clinically as an anti-anginal) that it was found to be a potent inhibitor of the carnitine shuttle. Inhibition of carnitine palmitoyl transferase-1 (CPT-1), and to a lesser extent, CPT-2 [24] led to secondary activation of glucose utilization via increased pyruvate dehydogenase activity, as a component of the "Randle cycle".

This metabolic shift in theory resulted in greater glucose utilization, and therefore increased ATP production. These findings therefore provide a potential explanation of the anti-ischaemic benefit of the drug. However, it was later shown that in working non-ischaemic rat hearts, perhexiline increased cardiac efficiency by approximately $30 \%$, without reduction of long-chain fatty acid utilization under these conditions [25]. As inhibition of CPT- 1 and 2 could not have accounted for all these effects, it has been suggested that there are additional mechanisms of therapeutic action. Indeed, subsequent studies showed that perhexiline possess some "anti-inflamematory" effects, including potentiation of nitric oxide [26]. It also inhibits superoxide formation in intact neutrophils, aortic valve interstitial cells, human umbilical vein endothelial cells and NADPH oxidase-2 [27] [28], and reduces expression of TXNIP in human cardiac tissue [29].

Clinically, beyond its well-known anti-anginal effect, clinical efficacy of perhexiline has also been demonstrated in symptomatic inoperable aortic stenosis [30], systolic heart failure [31] and in symptomatic non-obstructive hypertrophic cardiomyopathy [32]. In the latter study, despite the relatively short duration of treatment, perhexiline demonstrated improvement in myocardial energetic status (as measured by phosphocreatine to ATP ratios), oxygen consumption during peak exertion (peak $\mathrm{VO}_{2}$ ), ejection fraction and symptomatic status.

\subsection{Trimetazidine}

Trimetazidine inhibits 3-ketoacyl thiolase, the terminal enzyme involved in $\beta$-oxidation. It has therefore been shown to inhibit fatty acid oxidation in vitro and in vivo. It exerts moderate effects on exercise duration in patients with stable angina pectoris both as monotherapy [33] and in combination with $\beta$-blockers [34] [35]. It is widely used in Europe and Asia as anti-anginal treatment, without compromising haemodynamics. Similar to perhexiline, it has also been investigated in some small and relatively short clinical studies of heart failure, with promising endpoints focusing on left ventricular functions. Some of the studies also showed reduction in plasma cytokines and brain natriuretic peptide, suggesting its potential anti-inflammatory effect. However, it is noteworthy that there has been increasing reports of development of Parkinsonism after long-term treatment with trimetazidine. Although the rate is relatively low and the effect is usually reversible, such events should be evaluated and distinguished as a consequence of the individual agent or potentially of a particular drug class. 


\subsection{Ranolazine}

Ranolazine has been utilized as an anti-anginal agent only relatively recently, with evidence of moderate efficacy, rather similar to that of trimetazidine [36], and standard anti-anginal drugs [37]. Its main advantage has been freedom from major adverse effects, including safety in patients with heart failure. Initial studies suggested that ranolazine might act primarily as a partial fatty acid oxidation inhibitor [38]. However, more recently it has been suggested that inhibition of the late sodium current might contribute significantly to its anti-ischaemic effects [39]. Unlike perhexiline, human data on effects of ranolazine on myocardial energetic status are currently lacking. On the other hand, ranolazine appears to be devoid of major adverse effects.

\section{Conclusions}

There is an increasing evidence that elective coronary revascularization, except in the circumstance of surgical intervention for extensive ischaemia, lacks major prognostic impact. Furthermore, an increasing proportion of patients with severe stable angina pectoris are unsuitable for any form of coronary revascularization.

On the other hand, long-acting nitrates, $\beta$-blockers, and calcium antagonists are only moderately effective in improving angina symptoms, and there is therefore a considerable need for new anti-anginal drugs.

The emerging data suggest that ivabradine, allopurinol, trimetazidine, and ranolazine all offer some incremental effect, and can be utilized as “add-on” therapy in most patients, including those with impaired left ventricular systolic dysfunction. Perhexiline, while extremely potent as an anti-anginal agent, has potentially serious long-term toxicity and should be utilized only with therapeutic drug monitoring. There is no evidence that any of these agents is effective in treatment of angina induced by coronary vasomotor disorders: they appear to act essentially on the determinants of ATP availability to myocardium. The development of the "new" anti-ischaemic options serves to remind us of the need for further progress in this area.

\section{Acknowledgements}

This work was supported in part by a Program Grant from the Queen Elizabeth Hospital Research Foundation. C-R C is a recipient of an NHMRC Postgraduate Research Scholarship.

\section{References}

[1] Alderman, E.L., Bourassa, M.G., Cohen, L.S., Davis, K.B., Kaiser, G.G., Killip, T., Mock, M.B., Pettinger, M. and Robertson, T.L. (1990) Ten-Year Follow-Up of Survival and Myocardial Infarction in the Randomized Coronary Artery Surgery Study. Circulation, 82, 1629-1646. http://dx.doi.org/10.1161/01.CIR.82.5.1629

[2] Boden, W.E., O’Rourke, R.A., Teo, K.K., Hartigan, P.M., Maron, D.J., Kostuk, W.J., Knudtson, M., Dada, M., Casperson, P., Harris, C.L., Chaitman, B.R., Shaw, L., Gosselin, G., Nawaz, S., Title, L.M., Gau, G., Blaustein, A.S., Booth, D.C., Bates, E.R., Spertus, J.A., Berman, D.S., Mancini, G.B., Weintraub, W.S. and COURAGE Trial Research Group (2007) Optimal Medical Therapy with or without PCI for Stable Coronary Disease. The New England Journal of Medicine, 356, 1503-1516. http://dx.doi.org/10.1056/NEJMoa070829

[3] Munzel, T., Daiber, A. and Mulsch, A. (2005) Explaining the Phenomenon of Nitrate Tolerance. Circulation Research, 97, 618-628. http://dx.doi.org/10.1161/01.RES.0000184694.03262.6d

[4] Kleschyov, A.L., Oelze, M., Daiber, A., Huang, Y., Mollnau, H., Schulz, E., Sydow, K., Fichtlscherer, B., Mulsch, A. and Munzel, T. (2003) Does Nitric Oxide Mediate the Vasodilator Activity of Nitroglycerin? Circulation Research, 93, e104-112. http://dx.doi.org/10.1161/01.RES.0000100067.62876.50

[5] Walker, A., McMurray, J., Stewart, S., Berger, W., McMahon, A.D., Dargie, H., Fox, K., Hillis, S., Henderson, N.J. and Ford, I. (2006) Economic Evaluation of the Impact of Nicorandil in Angina (IONA) Trial. Heart, 92, 619-624. http://dx.doi.org/10.1136/hrt.2003.026385

[6] Fihn, S.D., Gardin, J.M., Abrams, J., Berra, K., Blankenship, J.C., Dallas, A.P., Douglas, P.S., Foody, J.M., Gerber, T.C., Hinderliter, A.L., King 3rd, S.B., Kligfield, P.D., Krumholz, H.M., Kwong, R.Y., Lim, M.J., Linderbaum, J.A., Mack, M.J., Munger, M.A., Prager, R.L., Sabik, J.F., Shaw, L.J., Sikkema, J.D., Smith Jr., C.R., Smith Jr., S.C., Spertus, J.A., Williams, S.V., F. American College of Cardiology, G. American Heart Association Task Force on Practice, P. American College of, S. American Association for Thoracic, A. Preventive Cardiovascular Nurses, A. Society for Cardiovascular, Interventions and S. Society of Thoracic (2012) 2012 ACCF/AHA/ACP/AATS/PCNA/SCAI/STS Guideline for the Diagnosis and Management of Patients with Stable Ischemic Heart Disease: A Report of the American College of Cardiology Foundation/American Heart Association Task Force on Practice Guidelines and the American College of Physicians, American Association for Thoracic Surgery, Preventive Cardiovascular Nurses Association, 
Society for Cardiovascular Angiography and Interventions and Society of Thoracic Surgeons. Journal of the American College of Cardiology, 60, e44-e164. http://dx.doi.org/10.1016/j.jacc.2012.07.013

[7] Opie, L.H. and Horowitz, J.D. (2012) Nitrates and Newer Antianginals. In: Opie, L.H. and Gersh, B.J., Eds., Drugs for the Heart, Elsevier, Amsterdam, 38-64.

[8] Fox, K., Ford, I., Steg, P.G., Tendera, M., Ferrari, R. and BEAUTIFUL Investigators (2008) Ivabradine for Patients with Stable Coronary Artery Disease and Left-Ventricular Systolic Dysfunction (BEAUTIFUL): A Randomised, Double-Blind, Placebo-Controlled Trial. Lancet, 372, 807-816. http://dx.doi.org/10.1016/S0140-6736(08)61170-8

[9] George, J., Carr, E., Davies, J., Belch, J.J. and Struthers, A. (2006) High-Dose Allopurinol Improves Endothelial Function by Profoundly Reducing Vascular Oxidative Stress and Not by Lowering Uric Acid. Circulation, 114, 2508-2516. http://dx.doi.org/10.1161/CIRCULATIONAHA.106.651117

[10] Ekelund, U.E., Harrison, R.W., Shokek, O., Thakkar, R.N., Tunin, R.S., Senzaki, H., Kass, D.A., Marban, E. and Hare, J.M. (1999) Intravenous Allopurinol Decreases Myocardial Oxygen Consumption and Increases Mechanical Efficiency in Dogs with Pacing-Induced Heart Failure. Circulation Research, 85, 437-445. http://dx.doi.org/10.1161/01.RES.85.5.437

[11] Stull, L.B., Leppo, M.K., Szweda, L., Gao, W.D. and Marban, E. (2004) Chronic Treatment with Allopurinol Boosts Survival and Cardiac Contractility in Murine Postischemic Cardiomyopathy. Circulation Research, 95, 1005-1011. http://dx.doi.org/10.1161/01.RES.0000148635.73331.c5

[12] Noman, A., Ang, D.S., Ogston, S., Lang, C.C. and Struthers, A.D. (2010) Effect of High-Dose Allopurinol on Exercise in Patients with Chronic Stable Angina: A Randomised, Placebo Controlled Crossover Trial. Lancet, 375, 2161-2167. http://dx.doi.org/10.1016/S0140-6736(10)60391-1

[13] Rajendra, N.S., Ireland, S., George, J., Belch, J.J., Lang, C.C. and Struthers, A.D. (2011) Mechanistic Insights into the Therapeutic Use of High-Dose Allopurinol in Angina Pectoris. Journal of the American College of Cardiology, 58, 820-828. http://dx.doi.org/10.1016/j.jacc.2010.12.052

[14] George, J. and Struthers, A. (2009) The OPT-CHF (Oxypurinol Therapy for Congestive Heart Failure) Trial: A Question of Dose. Journal of the American College of Cardiology, 53, 2405. http://dx.doi.org/10.1016/j.jacc.2008.07.076

[15] Kloner, R.A. and Nesto, R.W. (2008) Glucose-Insulin-Potassium for Acute Myocardial Infarction: Continuing Controversy over Cardioprotection. Circulation, 117, 2523-2533. http://dx.doi.org/10.1161/CIRCULATIONAHA.107.697979

[16] Howell, N.J., Ashrafian, H., Drury, N.E., Ranasinghe, A.M., Contractor, H., Isackson, H., Calvert, M., Williams, L.K., Freemantle, N., Quinn, D.W., Green, D., Frenneaux, M., Bonser, R.S., Mascaro, J.G., Graham, T.R., Rooney, S.J., Wilson, I.C. and Pagano, D. (2011) Glucose-Insulin-Potassium Reduces the Incidence of Low Cardiac Output Episodes after Aortic Valve Replacement for Aortic Stenosis in Patients with Left Ventricular Hypertrophy: Results from the Hypertrophy, Insulin, Glucose, and Electrolytes (HINGE) Trial. Circulation, 123, 170-177. http://dx.doi.org/10.1161/CIRCULATIONAHA.110.945170

[17] Randle, P.J., Sugden, P.H., Kerbey, A.L., Radcliffe, P.M. and Hutson, N.J. (1978) Regulation of Pyruvate Oxidation and the Conservation of Glucose. Biochemical Society Symposium, 43, 47-67.

[18] Horowitz, J.D., Chirkov, Y.Y., Kennedy, J.A. and Sverdlov, A.L. (2010) Modulation of Myocardial Metabolism: An Emerging Therapeutic Principle. Current Opinion in Cardiology, 25, 329-334. http://dx.doi.org/10.1097/HCO.0b013e328339f191

[19] Kennedy, J.A., Unger, S.A. and Horowitz, J.D. (1996) Inhibition of Carnitine Palmitoyltransferase-1 in Rat Heart and Liver by Perhexiline and Amiodarone. Biochemical Pharmacology, 52, 273-280. http://dx.doi.org/10.1016/0006-2952(96)00204-3

[20] Lyon, L.J., Nevins, M.A., Risch, S. and Henry, S. (1971) Perhexilene Maleate in Treatment of Angina Pectoris. Lancet, 297, 1272-1274. http://dx.doi.org/10.1016/S0140-6736(71)91783-1

[21] White, H.D. and Lowe, J.B. (1983) Antianginal Efficacy of Perhexiline Maleate in Patients Refractory to Beta-Adrenoreceptor Blockade. International Journal of Cardiology, 3, 145-155. http://dx.doi.org/10.1016/0167-5273(83)90030-X

[22] Cole, P.L., Beamer, A.D., McGowan, N., Cantillon, C.O., Benfell, K., Kelly, R.A., Hartley, L.H., Smith, T.W. and Antman, E.M. (1990) Efficacy and Safety of Perhexiline Maleate in Refractory Angina. A Double-Blind PlaceboControlled Clinical Trial of a Novel Antianginal Agent. Circulation, 81, 1260-1270. http://dx.doi.org/10.1161/01.CIR.81.4.1260

[23] Horowitz, J.D., Sia, S.T., Macdonald, P.S., Goble, A.J. and Louis, W.J. (1986) Perhexiline Maleate Treatment for Severe Angina Pectoris-Correlations with Pharmacokinetics. International Journal of Cardiology, 13, 219-229. http://dx.doi.org/10.1016/0167-5273(86)90146-4

[24] Kennedy, J.A. and Horowitz, J.D. (1998) Effect of Trimetazidine on Carnitine Palmitoyltransferase-1 in the Rat Heart. 
Cardiovascular Drugs and Therapy, 12, 359-363. http://dx.doi.org/10.1023/A:1007768716934

[25] Unger, S.A., Kennedy, J.A., McFadden-Lewis, K., Minerds, K., Murphy, G.A. and Horowitz, J.D. (2005) Dissociation between Metabolic and Efficiency Effects of Perhexiline in Normoxic Rat Myocardium. Journal of Cardiovascular Pharmacology, 46, 849-855. http://dx.doi.org/10.1097/01.fjc.0000190488.77434.f1

[26] Willoughby, S.R., Stewart, S., Chirkov, Y.Y., Kennedy, J.A., Holmes, A.S. and Horowitz, J.D. (2002) Beneficial Clinical Effects of Perhexiline in Patients with Stable Angina Pectoris and Acute Coronary Syndromes Are Associated with Potentiation of Platelet Responsiveness to Nitric Oxide. European Heart Journal, 23, 1946-1954. http://dx.doi.org/10.1053/euhj.2002.3296

[27] Gatto Jr., G.J., Ao, Z., Kearse, M.G., Zhou, M., Morales, C.R., Daniels, E., Bradley, B.T., Goserud, M.T., Goodman, K.B., Douglas, S.A., Harpel, M.R. and Johns, D.G. (2013) NADPH Oxidase-Dependent and -Independent Mechanisms of Reported Inhibitors of Reactive Oxygen Generation. Journal of Enzyme Inhibition and Medicinal Chemistry, 28, 95-104. http://dx.doi.org/10.3109/14756366.2011.636360

[28] Kennedy, J.A., Beck-Oldach, K., McFadden-Lewis, K., Murphy, G.A., Wong, Y.W., Zhang, Y. and Horowitz, J.D. (2006) Effect of the Anti-Anginal Agent, Perhexiline, on Neutrophil, Valvular and Vascular Superoxide Formation. European Journal of Pharmacology, 531, 13-19. http://dx.doi.org/10.1016/j.ejphar.2005.11.058

[29] Ngo, D.T., Drury, N.E., Pagano, D., Frenneaux, M.P. and Horowitz, J.D. (2011) How Does Perhexiline Modulate Myocardial Energetics and Ameliorate Redox Stress? Abstract. AHA 2011. Circulation, 124, Article ID: A14461.

[30] Unger, S.A., Robinson, M.A. and Horowitz, J.D. (1997) Perhexiline Improves Symptomatic Status in Elderly Patients with Severe Aortic Stenosis. Australian and New Zealand Journal of Medicine, 27, 24-28. http://dx.doi.org/10.1111/j.1445-5994.1997.tb00909.x

[31] Lee, L., Campbell, R., Scheuermann-Freestone, M., Taylor, R., Gunaruwan, P., Williams, L., Ashrafian, H., Horowitz, J., Fraser, A.G., Clarke, K. and Frenneaux, M. (2005) Metabolic Modulation with Perhexiline in Chronic Heart Failure: A Randomized, Controlled Trial of Short-Term Use of a Novel Treatment. Circulation, 112, 3280-3288. http://dx.doi.org/10.1161/CIRCULATIONAHA.105.551457

[32] Abozguia, K., Elliott, P., McKenna, W., Phan, T.T., Nallur-Shivu, G., Ahmed, I., Maher, A.R., Kaur, K., Taylor, J., Henning, A., Ashrafian, H., Watkins, H. and Frenneaux, M. (2010) Metabolic Modulator Perhexiline Corrects Energy Deficiency and Improves Exercise Capacity in Symptomatic Hypertrophic Cardiomyopathy. Circulation, 122, 15621569. http://dx.doi.org/10.1161/CIRCULATIONAHA.109.934059

[33] Brottier, L., Barat, J.L., Combe, C., Boussens, B., Bonnet, J. and Bricaud, H. (1990) Therapeutic Value of a Cardioprotective Agent in patients with Severe Ischaemic Cardiomyopathy. European Heart Journal, 11, 207-212.

[34] Chazov, E.I., Lepakchin, V.K., Zharova, E.A., Fitilev, S.B., Levin, A.M., Rumiantzeva, E.G. and Fitileva, T.B. (2005) Trimetazidine in Angina Combination Therapy-The TACT Study: Trimetazidine versus Conventional Treatment in Patients with Stable Angina Pectoris in a Randomized, Placebo-Controlled, Multicenter Study. American Journal of Therapeutics, 12, 35-42. http://dx.doi.org/10.1097/00045391-200501000-00006

[35] Szwed, H., Sadowski, Z., Elikowski, W., Koronkiewicz, A., Mamcarz, A., Orszulak, W., Skibinska, E., Szymczak, K., Swiatek, J. and Winter, M. (2001) Combination Treatment in Stable Effort Angina Using Trimetazidine and Metoprolol: Results of a Randomized, Double-Blind, Multicentre Study (TRIMPOL II). European Heart Journal, 22, 22672274. http://dx.doi.org/10.1053/euhj.2001.2896

[36] Danchin, N., Marzilli, M., Parkhomenko, A. and Ribeiro, J.P. (2011) Efficacy Comparison of Trimetazidine with Therapeutic Alternatives in Stable Angina Pectoris: A Network Meta-Analysis. Cardiology, 120, 59-72. http://dx.doi.org/10.1159/000332369

[37] Chaitman, B.R., Pepine, C.J., Parker, J.O., Skopal, J., Chumakova, G., Kuch, J., Wang, W., Skettino, S.L., Wolff, A.A. for Combination Assessment of Ranolazine in Stable Angina Investigators (2004) Effects of Ranolazine with Atenolol, Amlodipine, or Diltiazem on Exercise Tolerance and Angina Frequency in Patients with Severe Chronic Angina: A Randomized Controlled Trial. JAMA, 291, 309-316. http://dx.doi.org/10.1001/jama.291.3.309

[38] Zacharowski, K., Blackburn, B. and Thiemermann, C. (2001) Ranolazine, a Partial Fatty Acid Oxidation Inhibitor, Reduces Myocardial Infarct Size and Cardiac Troponin T Release in the Rat. European Journal of Pharmacology, 418, 105-110. http://dx.doi.org/10.1016/S0014-2999(01)00920-7

[39] Belardinelli, L., Shryock, J.C. and Fraser, H. (2006) Inhibition of the Late Sodium Current as a Potential Cardioprotective Principle: Effects of the Late Sodium Current Inhibitor Ranolazine. Heart, 92, iv6-iv14. http://dx.doi.org/10.1136/hrt.2005.078790

[40] Parker, J.O., Amies, M.H., Hawkinson, R.W., Heilman, J.M., Hougham, A.J., Vollmer, M.C., Wilson, R.R. and Minitran Efficacy Study Group (1995) Intermittent Transdermal Nitroglycerin Therapy in Angina Pectoris. Clinically Effective without Tolerance or Rebound. Circulation, 91, 1368-1374. http://dx.doi.org/10.1161/01.CIR.91.5.1368

[41] Chrysant, S.G., Glasser, S.P., Bittar, N., Shahidi, F.E., Danisa, K., Ibrahim, R., Watts, L.E., Garutti, R.J., Ferraresi, R. 
and Casareto, R. (1993) Efficacy and Safety of Extended-Release Isosorbide Mononitrate for Stable Effort Angina Pectoris. American Journal of Cardiology, 72, 1249-1256. http://dx.doi.org/10.1016/0002-9149(93)90292-K

[42] Jamal, S.M., Freedman, S.B., Thomson, A., Carter, G., Harris, P.J. and Kelly, D.T. (1987) Antianginal Efficacy of Carvedilol, a New Beta-Blocker with Vasodilating Action. Journal of Cardiovascular Pharmacology, 10, S141-S146. http://dx.doi.org/10.1097/00005344-198710110-00026

[43] Schnellbacher, K., Marsovszky, E. and Roskamm, H. (1986) Effect of Bisoprolol on Exercise Tolerance in Patients with Coronary Heart Disease: Placebo-Controlled Double-Blind Crossover Study. Journal of Cardiovascular Pharmacology, 8, S143-S147. http://dx.doi.org/10.1097/00005344-198511001-00026

[44] DiBianco, R., Singh, S., Singh, J.B., Katz, R.J., Bortz, R., Gottdiener, J.S., Spodick, D.H., Laddu, A.R. and Fletcher, R.D. (1980) Effects of Acebutolol on Chronic Stable Angina Pectoris. A Placebo-Controlled, Double-Blind, Randomized Crossover Study. Circulation, 62, 1179-1187. http://dx.doi.org/10.1161/01.CIR.62.6.1179

[45] Schwartz, J.B., Jackson, G., Kates, R.E. and Harrison, D.C. (1981) Long-Term Benefit of Cardioselective Beta Blockade with Once-Daily Atenolol Therapy in Angina Pectoris. American Heart Journal, 101, 380-385. http://dx.doi.org/10.1016/0002-8703(81)90125-3

[46] Hung, J., Lamb, I.H., Connolly, S.J., Jutzy, K.R., Goris, M.L. and Schroeder, J.S. (1983) The Effect of Diltiazem and Propranolol, Alone and in Combination, on Exercise Performance and Left Ventricular Function in Patients with Stable Effort Angina: A Double-Blind, Randomized, And Placebo-Controlled Study. Circulation, 68, 560-567. http://dx.doi.org/10.1161/01.CIR.68.3.560

[47] Pine, M.B., Citron, P.D., Bailly, D.J., Butman, S., Plasencia, G.O., Landa, D.W. and Wong, R.K. (1982) Verapamil versus Placebo in Relieving Stable Angina Pectoris. Circulation, 65, 17-22. http://dx.doi.org/10.1161/01.CIR.65.1.17

[48] Andreasen, F., Boye, E., Christoffersen, E., Dalsgaard, P., Henneberg, E., Kallenbach, A., Ladefoged, S., Lillquist, K., Mikkelsen, E., Norder, E., Olsen, J., Pedersen, J.K., Pedersen, V., Petersen, G.B., Schroll, J., Schultz, H. and Seidelin, J. (1975) Assessment of Verapamil in the Treatment of Angina Pectoris. European Journal of Cardiology, 2, 443-452.

[49] Borer, J.S., Fox, K., Jaillon, P., Lerebours, G. and Ivabradine Investigators Group (2003) Antianginal and Antiischemic Effects of Ivabradine, an $\mathrm{I}_{\mathrm{f}}$ Inhibitor, in Stable Angina: A Randomized, Double-Blind, Multicentered, Placebo-Controlled Trial. Circulation, 107, 817-823. http://dx.doi.org/10.1161/01.CIR.0000048143.25023.87

[50] Tardif, J.C., Ponikowski, P., Kahan, T. for the ASSOCIATE study Investigators (2009) Efficacy of the $\mathrm{I}_{\mathrm{f}}$ Current Inhibitor Ivabradine in Patients with Chronic Stable Angina Receiving Beta-Blocker Therapy: A 4-Month, Randomized, Placebo-Controlled Trial. European Heart Journal, 30, 540-548. http://dx.doi.org/10.1093/eurheartj/ehn571 
Scientific Research Publishing (SCIRP) is one of the largest Open Access journal publishers. It is currently publishing more than 200 open access, online, peer-reviewed journals covering a wide range of academic disciplines. SCIRP serves the worldwide academic communities and contributes to the progress and application of science with its publication.

Other selected journals from SCIRP are listed as below. Submit your manuscript to us via either submit@scirp.org or Online Submission Portal.
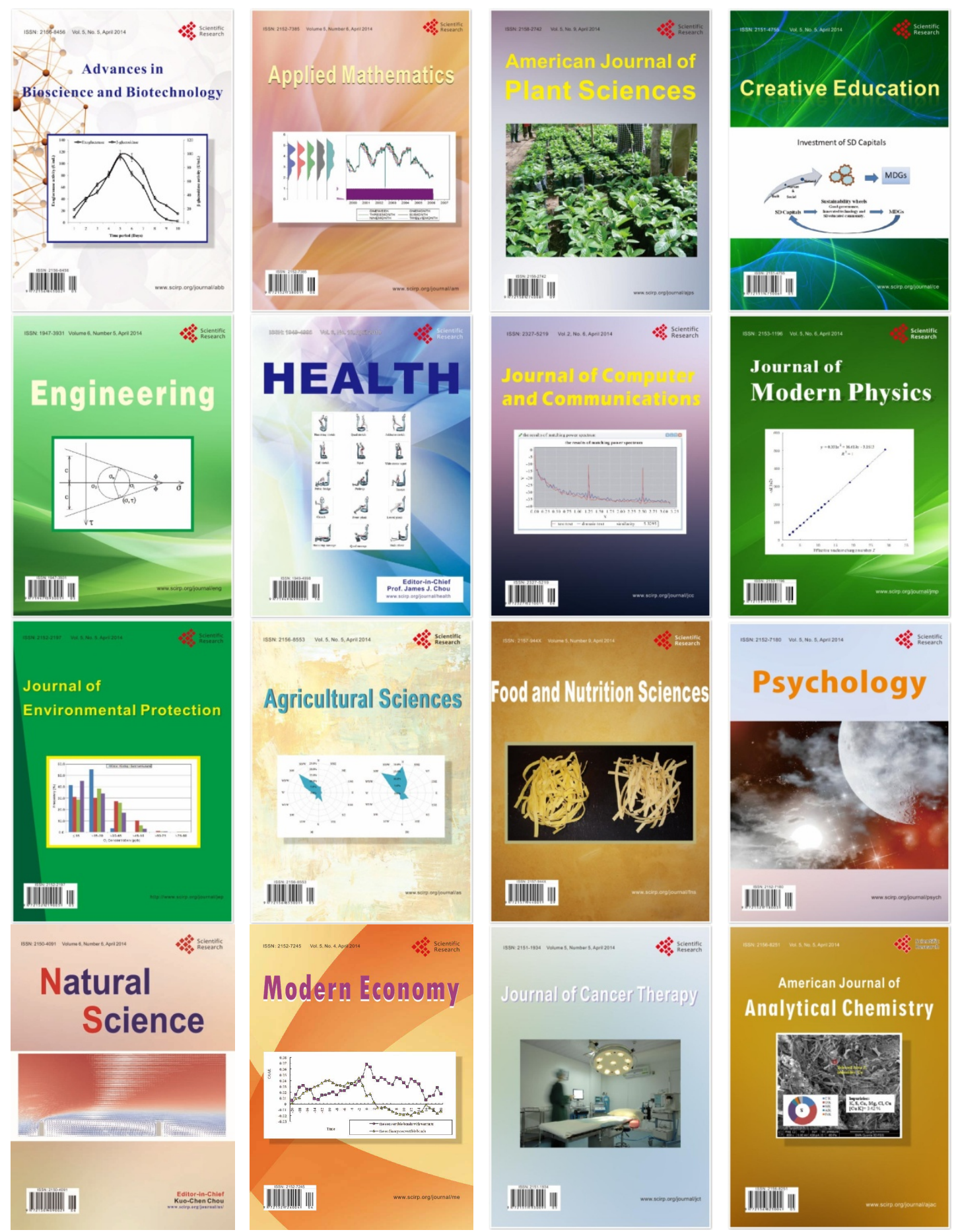